\title{
Peyronie's disease may negatively impact the sexual experience of a couple and female sexual function: a single center study
}

\author{
Ester Illiano ${ }^{1}$, Francesco Trama ${ }^{1}$, Vito Mancini ${ }^{2}$, Antonio Ruffo ${ }^{3}$, Giuseppe Romeo ${ }^{4}$, Filippo Riccardo ${ }^{5}$, \\ Consuelo Fabi ${ }^{1}$, Giuseppe Carrieri ${ }^{2}$, Felice Crocetto ${ }^{5}$, Fabrizio Iacono ${ }^{5}$, Elisabetta Costantini ${ }^{1}$ \\ ${ }^{1}$ Andrology and Urogynecology Clinic, Santa Maria Terni Hospital, University of Perugia, Terni, Italy; ${ }^{2}$ Urology and Kidney Transplantation Unit \\ Ospedali Riuniti, University of Foggia, Foggia, Italy; ${ }^{3}$ Andrea Grimaldi Hospital, San Giorgio a Cremano (NA), Italy; ${ }^{4}$ Urology Department, A.O.R.N. \\ A. Cardarelli, Naples, Italy; ${ }^{5}$ Department of General and Specialized Surgeries, Renal Transplantation, Nephrology, Intensive Care and Pain \\ Management, University of Naples "Federico II", Napoli, Italy \\ Contributions: (I) Conception and design: F Trama, E Illiano, E Costantini; (II) Administrative support: G Romeo, F Riccardo, F Iacono, G Carrieri; \\ (III) Provision of study materials or patients: A Ruffo, F Crocetto, V Mancini, E Illiano, E Costantini; (IV) Collection and assembly of data: A \\ Ruffo, F Iacono, E Costantini, G Carrieri, F Crocetto; (V) Data analysis and interpretation: F Trama, E Illiano, C Fabi; (VI) Manuscript writing: All \\ authors; (VII) Final approval of manuscript: All authors. \\ Correspondence to: Francesco Trama. Andrology and Urogynecology Clinic, Santa Maria Terni Hospital, University of Perugia, Via tristano di \\ Joannuccio 1 - 05100 Terni, Italy. Email: francescotrama@gmail.com.
}

Background: Peyonie's disease (PD) mostly affects males in the fifth decade of life, with a prevalence in the general population ranging between $0.5 \%$ and $20.3 \%$. The pathology of PD is characterized by fibrosis of the tunic albuginea of the cavernous bodies of the penis, with the presence of pain in the erection and penile deformity. This is associated with decreased sexual function for both participants. The objective of the study was to investigate the influence of PD pathology on both male patients' and their female partners' sexual spheres, and analyze changes in sexual function and perception following penile correction surgery.

Methods: Prospective study, we included male patients with PD and their female partner sexually active. Patients underwent corporoplasty with multiple plications. The male and female sexuality was evaluated before surgery and three months after male treatment by the Female sexual Function Index (FSFI); International Index of Erectile Function (IIEF); Visual Analogical Scale (VAS).

Results: From January 2018 to November 2019 we included 35 couple. The female subjects before partner's surgery presented dyspareunia, loss of sexual desire, inability to achieve orgasm, and sexual dissatisfaction. At three months after surgical treatment there was an improvement of sexual function in both male patients and female partners (desire $\mathrm{P}<0.0001$, arousal $\mathrm{P}<0.0001$, lubrification $\mathrm{P}<0.0001$, orgasm $\mathrm{P}<0.0001$, satisfaction $\mathrm{P}<0.0001$, pain $\mathrm{P}<0.0001)$. As regarding male patients the pain decreased significantly (VAS score from 6 to 2.5), while there was no statistically significant improvement in erectile function $(\mathrm{P}=0.05)$.

Conclusions: Our findings suggest that a viable approach to treatment of PD patients that involves their partners could lead to better functional and psychological results.

Keywords: Relationship factors; Peyronie's disease (PD); male sexuality; female sexuality

Submitted Jul 06, 2020. Accepted for publication Nov 26, 2020.

doi: $10.21037 /$ tau-20-1067

View this article at: http://dx.doi.org/10.21037/tau-20-1067

\section{Introduction}

Peyronie's disease (PD) usually affects men between 55 and 60 years of age, with a prevalence between $0.5 \%$ and
$20.3 \%$ (1). It is characterized by disorder of the albuginea tunic, in which fibrotic plaques appear and calcify. Plaques mostly develop in the dorsal area, and can evoke pain during 
erection and in the penile deformity (2).

The pathophysiological mechanism of PD is controversial. A likely hypothesis is that PD develops as a result of an inflammatory response following penile trauma (2-5), or an autoimmune response (6).

The pathology of PD develops in two phases. The acute, or inflammatory, phase is typically associated with pain in the erection, a palpable penile plaque, and an evolving deformity (7). The second "stable" phase is characterized by penile deformity stabilization, plaque stabilization, and pain resolution (8). In addition, disease progression can lead to erectile dysfunction, which can aggravate the psychological impact of PD (9).

The treatment involves oral treatment (Potassium ParaAminobenzoate (POTABA), vitamin E, colchicine, omega-3, procarbazine, tamoxifen, carnitine, and pentoxifylline) (10), infiltration of collagenase obtained from Clostridium bistolyticum (11) ; while for the treatment of local pain the use of low-intensity shock waves (Li - ESWT) (12), and surgery for patients with stabilized disease following at least 6 to 12 months of onset $(13,14)$.

From a psychological point of view, the progression of the pathology leads to difficulties in penetration, decreased sexual sensation, and a subsequent decrease in the frequency of sexual intercourse, leading to social isolation and depression (15). Furthermore $48 \%$ of men with PD had depressive symptoms and $54 \%$ of men describing relationship difficulties and fear of not satisfying their partners $(15,16)$. Therefore, PD can be defined by a pathology that generally affects couples' sexual spheres. In literature there were few data on how female partners are affected by the disease.

The primary objective of this study was to assess sexual functions of PD patient's partners before and after surgical curvature correction treatment. The secondary objective was to evaluate the patient's sexual experience and pain perception during penetration before and after treatment. We present the following article in accordance with the MDAR reporting checklist (available at: http://dx.doi. org/10.21037/tau-20-1067).

\section{Methods}

\section{Subjects}

All procedures performed in this study were in accordance with the Declaration of Helsinki (as revised in 2013). This was a prospective observational study, approved by the local ethics committee (Bioethical committee, Unipg $\left.N^{\circ} 36367\right)$. Each subject was informed about the purpose of the investigation and provided informed consent. The inclusion criteria for male subjects included $>18$ years of age with penile deformity between $30^{\circ}-60^{\circ}$ with onset at least 12 months prior, with absence of pain in erection, who underwent corporoplasty with multiple plications. Couples must have had a sexual relationship lasting $\geq 6$ months at the time of the study. The inclusion criteria for partners included female partners of PD patients undergoing corporoplasty with multiple plications, aged $>18$ years.

Exclusion criteria included male patients with penile deformity $>60^{\circ}$ or persistent curvature for fewer than 12 months, hourglass curvature, an International Index of erectile function 15 (IIEF15) questionnaire with evaluation of erectile function subdomain $\leq 25,<18$ years old, patients who underwent previous penile surgery, and female partners undergoing pelvic surgery within one year.

The demographic and clinical data of male and female partners were collected. Preoperative evaluation of PD patients included anamnesis; local examination, measurement, and deviation of penile deformity, measured with a goniometer while having an erection obtained by intracavernous injection of Alprostadil (10 mcg); B-mode ultrasound to measure plaque length; and administration of the Visual analogic scale (VAS, score 0-10) questionnaire to quantify penile pain during vaginal penetration (17). In addition, the IIEF 15 questionnaire was administered to assess the following domains: erectile function (items 1-5 and 15), orgasmic function (items 9-10), sexual desire (items 11-12), intercourse satisfaction (items 6-8), and overall satisfaction (items 13-14) (18).

During the preoperative phase, the female partner was given the Functional Sexual Function Index (FSFI) questionnaire, which comprises 19 items encompassing 6 domains: desire (items 1-2), arousal (items 3-6), lubrication (items 7-10), orgasm (items 11-13), satisfaction (items 14-16), and pain (items 17-19) (19). Single domain scores on the FSFI range from 0 to 6 , with a higher score indicating better sexual function and less pain, and a score of zero indicating no sexual activity during the previous 4 weeks. An FSFI total score of 26.55 or less indicates that females may have sexual dysfunction (20).

In the postoperative phase the curvature was measured with a goniometer while having an erection obtained by intracavernous injection of Alprostadil (10 mcg).

The two partners completed their questionnaire individually in different rooms. 
Table 1 Preoperative demographic data

\begin{tabular}{ll}
\hline Parameters & Value \\
\hline Female age (mean \pm SD) & $54.5 \pm 11.9$ \\
Menopause, $\mathrm{n}(\%)$ & $35(100.0)$ \\
Male age (mean $\pm \mathrm{SD})$ & $57.5 \pm 11.4$ \\
Married, $\mathrm{n}(\%)$ & $23(65.7)$ \\
Cohabitating, $\mathrm{n}(\%)$ & $4(11.4)$ \\
Non cohabitating, $\mathrm{n}(\%)$ & $8(22.8)$ \\
FSFI score (median, range) & $25.5[10-63]$ \\
IIEF score erectile function (median, range) & $23[18-29]$ \\
Male partner VAS score (median, range) & $6[2-9]$ \\
\hline
\end{tabular}

\section{Surgical procedure}

The first surgical procedure used to treat $\mathrm{PD}$ was described by Nesbit in 1965 (21). This procedure consists of the transverse excision of an ellipse of albugineous tunic of approximately $1 \mathrm{~mm}$ every $10^{\circ}$ of curvature (22). For this study, we enrolled patients undergoing a Nesbit modified corporoplasty according to our technique (23). The procedure consisted of making single or multiple longitudinal incisions on the convex side of the curvature and then closing them horizontally (24). After circumcision, a tourniquet was placed at the base of the penis and an artificial erection was induced by injecting sterile saline with a 19-gauge butterfly needle. In this way, it was possible to highlight the curvature angle. Careful degloving of the bands was performed by minimizing bleeding. Subsequently, the final plications that were performed were simulated with Allis pliers, paying attention to the nerve bundle. Absorbable sutures (PDS 2.0) were used against the side at the point of maximum curvature. For ventral curvatures, the same technique was performed following isolation of the nerve bundle in advance. Subsequently, a new artificial erection was performed to verify the result of the pleating. The buck fascia was closed with rapidly absorbing detached 3.0 points. The skin was sutured using rapidly resorbed 4.0 detached points. A bladder catheter was inserted for $24 \mathrm{~h}$, and a compression dressing was applied. The surgical procedure was performed by 2 senior surgeons. The followup was performed by a surgeon other than the one who performed the surgical procedure. The couple could resume sexual activity after at least 6 weeks.

Patients were followed up 3 months after surgery. The postoperative evaluation included anamnesis, objective examination, female partners filling in the FSFI long form, and male partners filling in the IIEF 15 and VAS questionnaire to record pain during penetration. In addition, a new intracavernous injection with Alprostadil $(10 \mathrm{mcg})$ was used to assess any residual curvatures.

\section{Statistical analysis}

Statistical analysis was performed using the McNemar Chi-Square test to compare paired categorical variables, paired $t$-tests were used for continuous parametric variables. The Wilcoxon and Kruskal-Wallis tests were used for quantitative variables of mean and median values, respectively. All calculations were performed using IBMSPSS $^{\circledR}$ version 22.0 (IBM Corp., Armonk, NY, USA, 2013). $\mathrm{P}$ value $<0.05$ was considered to be statistically significant.

\section{Results}

From January 2018 to November 2019, 49 couples met the inclusion criteria, of which 35 completed the diagnostic and therapeutic process correctly. Thus, they were included in the study.

The demographic characteristics of the couples are presented in Table 1. The female mean age was $54.5 \pm 11.9$ years and male age $57.5 \pm 11.4$ years. Of the couples, $65.7 \%$ were married, $22.8 \%$ were unmarried, and $11.4 \%$ were cohabiting.

The clinical characteristics of the men affected by PD are listed in Table 2 . The mean penile deformity was $53.4 \pm 9.1^{\circ}$, and was found mostly dorsal (51.4\% of patients) with plates 1-2 cm in size. The median FSFI score 25.5 (range, 10-63), with greater impairment in the orgasmic phase and the presence of pain during sexual intercourse. All women were in menopause, they had vaginal pain during penetration, associated with poor desire and vaginal lubrication.

Three months after the surgical procedure, all FSFI domains score improved significantly $(\mathrm{P}<0.0001)$, with female partners reporting satisfaction with sexual intercourse and decreasing pain and discomfort in $85 \%$ of cases (30 women); $15 \%$ of women had persistent low lubrification and pain during vaginal penetration (Table 3). At three months follow-up, male patients reported an improvement in 4 domains of the IIEF-15, including desire $(\mathrm{P}=0.003)$ and both general and sexual satisfaction $(\mathrm{P}<0.0001 ;$ Table 4). After surgery, there was no statistically significant improvement in erectile function $(\mathrm{P}=0.05)$. 
Patients with persistent erectile dysfunction were treated with PDE5i and obtained satisfactory sexual intercourse. Pain decreased significantly, with a median VAS value from 6 to 2.5 (Table 5). At follow-up, $97.1 \%$ of patients had no residual curvature. One patient exhibited residual curvature of $<20^{\circ}$ but did not require further treatment.

\section{Discussion}

Our study showed that PD has a negative impact on the sexuality of the female partner as well as the male patient, and that surgical treatment improves the sexual experience of the couple. Gelbard et al. [1990] reported that $77 \%$ of men with PD experience negative psychological effects (24). PD patients express embarrassment, loss of sexual confidence, anxiety to the point of depression, and impairment of social relationships at home, work, and with their partner (13). Smith et al. reported that of 245 patients with $\mathrm{PD}, 81 \%$ had emotional problems and $54 \%$ had

Table 2 Pre and postoperative clinical data of male patients

\begin{tabular}{lll}
\hline Clinical data & Preoperative & Postoperative \\
\hline $\begin{array}{l}\text { Mean penile curvature }( \pm \text { SD) } \\
\text { Direction of curvature }\end{array}$ & $53.4^{\circ}( \pm 9.1)$ & $0.1^{\circ}( \pm 0.9)$ \\
Dorsal, $\mathrm{n}(\%)$ & $18(51.4)$ & $1(2.8)$ \\
Ventral, $\mathrm{n}(\%)$ & $3(8.5)$ & 0 \\
Lateral, $\mathrm{n}(\%)$ & $14(40.0)$ & 0 \\
Plaques length, $\mathrm{n}(\%)$ & & \\
$<1 \mathrm{~cm}$ & $13(37,1)$ & $16(45.7)$ \\
$1-2 \mathrm{~cm}$ & $15(42.9)$ & $13(37.1)$ \\
$>2 \mathrm{~cm}$ & $7(20.0)$ & $6(17.1)$ \\
\hline
\end{tabular}

relationship problems related to the disease (16).

In our study, all patients showed impairment of sexual function before surgical treatment, similar to findings by Rosent (25). Rosent's study reported that patients with PD felt embarrassment towards themselves, loss of their virility because of penile deformity, and fear of not satisfying their partner sexually (25).

Numerous studies in the literature demonstrated the negative impact of erectile dysfunction (26) and premature ejaculation (27). However, the impact of PD on the sexuality of a female partner, and how they perceive their partner's inability to have satisfactory sexual relations, has not been well investigated. The female partners in our sample had low scores in all FSFI domains before treatment \{median total score 25.5 [10-63]\}. They presented with dyspareunia \{median 3 [1-14]\}, loss of sexual desire \{median $4[1-10]\}$, inability to achieve orgasm \{median 3 [1-13]\}, and sexual dissatisfaction \{median 4 [1-15]\}.Three months after surgery showed a marked improvement in all domains $(\mathrm{P}<0.0001)$ in $85 \%$ of women. It is likely that the alteration of female sexual function begins because of male sexual dysfunction, but over time, the partners fall into a "vicious circle" in which each becomes cause and also effect (28). Coital pain remains at the base of such a "vicious circle" and the consequent "sexual crisis" experienced by a couple. In fact, dyspareunia in this case is considered a "couple's pain". The patient experiences pain due to $\mathrm{PD}$, often during ejaculation when the erection peaks (2) the woman likely has pain during attempted penetration. All female partners were in menopause and the presence of dyspareunia and decreased vaginal lubrication could be considered within the genitourinary syndrome of menopause. However, the improvement of symptoms, in $85 \%$ of women, after the partner's surgery, could suggest

Table 3 Pre and postoperative FSFI subdomains

\begin{tabular}{lccc}
\hline Domain & Baseline score, median (range) & Last visit score, median (range) & P value \\
\hline Desire & $4[1-10]$ & $8[3-10]$ & $<0.0001$ \\
Arousal & $4[1-14)$ & $13[7-20]$ & $<0.0001$ \\
Lubrification & $4[1-15]$ & $13.50[5-20]$ & $<0.0001$ \\
Orgasm & $3[1-13]$ & $11.50[6-18]$ & $<0.0001$ \\
Satisfaction & $4[1-15]$ & $11.50[6-19]$ & $<0.0001$ \\
Pain & $3[1-14]$ & $11[7-15]$ & $<0.0001$ \\
FSFI total score & $25.5[10-63]$ & $45[27-78]$ & $<0.0001$ \\
\hline
\end{tabular}


Table 4 Pre and postoperative subdomains of IIEF 15

\begin{tabular}{lccc}
\hline Subdomain of IIEF 15 & Score preoperative (median, range) & Score postoperative (median, range) & P value \\
\hline Erectile function & $23[18-29]$ & $25[18-30]$ & 0.5 \\
Orgasmic function & $4[0-10]$ & $7[3-10]$ & 0.002 \\
Sexual desire & $4[2-10]$ & $7[3-10]$ & 0.003 \\
Intercourse satisfaction & $6[0-11]$ & $9[5-15]$ & 0.0001 \\
Overall satisfaction & $5[2-8]$ & $7[3-10]$ & 0.0001 \\
\hline
\end{tabular}

Table 5 Pre and postoperative VAS score in the male

\begin{tabular}{lccc}
\hline VAS score & Score preoperative & Score postoperative & $P$ value \\
\hline Median (range) & $6[2-9]$ & $2.5[0-7]$ & 0.0001 \\
\hline
\end{tabular}

that in these women the preoperative sexual dysfunction was not linked to menopause but to a discomfort of the couple. The persistence of symptoms in $15 \%$ of the cases could be related to the genitourinary syndrome of menopause.

The mechanism of vaginal pain, lubrications much more complex.

Dyspareunia directly interferes with excitement. In fact, pain is the most powerful reflex inhibitor of genital arousal, as well as the lubrication and congestion phase (29). This causes vaginal dryness and makes penetration even more painful, difficult, or impossible (30). Indirectly, lower congestion reduces or prevents the formation of the orgasmic platform, so that orgasm (especially coital) becomes difficult or impossible (31). Pain, dissatisfaction, and disappointment then provoke a progressive inhibition of desire and other sexual functions, leading to a frank avoidance of erotic intimacy.

The female orgasm is achieved by local stimulation of the clitoris, or of the vulva, vagina, and other perineal regions. Vaginal orgasm doesn't have any scientific basis. Orgasmic dysfunction in women is difficult to investigate, in fact some women experience orgasm by local stimulation, whereas other solely from sexual intercourse, and some women never experience orgasm (32). In these women an alteration of orgasm could be attributed to the depressive state, anxiety, fear of the partner, and also to the difficulty to relate to the partner out of shame (33).

As a result of surgical correction, male sexual function improved, as well as that of the female partner. Similar results have been reported also after treatment by Collagenase Clostridium histolyticum (CCH; Xiapex) injection, in men with stable PD $(34,35)$. Both in Cocci's study (34) and in Goldstein's study (35) after injections there was an improvement both male and female partners, reported improvement sexual symptoms. Before male partner treatment the percentage of female sexual partners with sexual dysfunction was $75.0 \%$ and the after surgery decreased to $33.3 \%$. This result is in agreement with our ( $85 \%$ versus $15 \%$ with persistent sexual symptoms).

The percentage of female sexual partners with sexual dysfunction (FSFI total score $\leq 26.55$ ) also decreased after male partner treatment, from $75.0 \%$ at baseline to $33.3 \%$. Also in an another studies for erectile dysfunction $(36,37)$ further demonstrating that treating the male is, to some degree, treating the couple. Based on this evidence, Greenstein et al. advised urologists to always perform a thorough sexual history of the couple in the presence of patients with sexual dysfunction (38).

The strengths of this study included the prospective design, contemporary evaluation of the sexual functions of female partners and male PD patients, and the lack of similar studies in the literature. The limitations include the absence of a control group, a small sample size and the lack of long-term follow-up, and not having investigated the possible use of PDE5i.

\section{Conclusions}

Our study shows that PD, like other male sexual dysfunctions, could have a negative impact on female sexual function, investigating with standardized questionnaires.

Treatment of the disease led to improved sexual function in both partners. Therefore, urologists should always investigate the sexual function of the couple, if stable. An 
approach to the couple, rather than to the patient alone, could improve the perception of the pathology by both, with better functional and psychological results. These findings warrant further investigations on this topic, and raise the awareness of urologists regarding the management of this pathology, perhaps with a multidisciplinary approach involving other professional figures, such as a psychosexologist.

\section{Acknowledgments}

Funding: None.

\section{Footnote}

Reporting Checklist: The authors have completed the MDAR reporting checklist. Available at http://dx.doi.org/10.21037/ tau-20-1067

Conflicts of Interest: All authors have completed the ICMJE uniform disclosure form (available at http://dx.doi. org/10.21037/tau-20-1067). The authors have no other conflicts of interest to declare.

Ethical Statement: The authors are accountable for all aspects of the work in ensuring that questions related to the accuracy or integrity of any part of the work are appropriately investigated and resolved. All procedures performed in this study were in accordance with the Declaration of Helsinki (as revised in 2013). This was a prospective observational study, approved by the local ethics committee (bioethical committee No. 36367). Each subject was informed about the purpose of the investigation and provided informed consent.

Open Access Statement: This is an Open Access article distributed in accordance with the Creative Commons Attribution-NonCommercial-NoDerivs 4.0 International License (CC BY-NC-ND 4.0), which permits the noncommercial replication and distribution of the article with the strict proviso that no changes or edits are made and the original work is properly cited (including links to both the formal publication through the relevant DOI and the license). See: https://creativecommons.org/licenses/by-nc-nd/4.0/.

\section{References}

1. Nehra A, Alterowitz R, Culkin DJ, et al. Peyronie's
Disease: AUA Guideline. J Urol 2015;194:745-53.

2. Pryor JP, Ralph DJ. Clinical presentations of Peyronie's disease. Int J Impot Res 2002;14:414-7.

3. Somers KD, Sismour EN, Wright GL Jr, et al. Isolation and characterization of collagen in Peyronie's disease. J Urol 1989;141:629-31.

4. Somers KD, Dawson DM. Fibrin deposition in Peyronie's disease plaque. J Urol 1997;157:311-5.

5. Jiang $\mathrm{H}, \mathrm{Gao} \mathrm{Q}, \mathrm{Che} \mathrm{X}$, et al. Repeated Micro-Trauma of the Penile Tunica Albuginea: A New Animal Model of Peyronie's Disease. Urol Int 2018;100:228-39.

6. Ralph DJ, Mirakian R, Pryor JP, et al. The immunological features of Peyronie's disease. J Urol 1996;155:159-62.

7. Levine L, Rybak J, Corder C, et al. Peyronie's disease plaque calcification--prevalence, time to identification, and development of a new grading classification. J Sex Med 2013;10:3121-8.

8. Brimley SC, Yafi FA, Greenberg J, et al. Hatzichristodoulou G. Review of Management Options for Active-Phase Peyronie's Disease. Sex Med Rev 2019;7:329-37.

9. Burri A, Porst $H$. The relationship between penile deformity, age, psychological bother, and erectile dysfunction in a sample of men with Peyronie's Disease (PD). Int J Impot Res 2018;30:171-8.

10. Barrett-Harlow B, Wang R. Oral therapy for Peyronie's disease, does it work? Transl Androl Urol 2016;5:296-302

11. Abdel Raheem A, Johnson M, Abdel-Raheem T, et al. Collagenase Clostridium histolyticum in the Treatment of Peyronie's Disease-A Review of the Literature and a New Modified Protocol. Sex Med Rev 2017;5:529-35.

12. Gao L, Qian S, Tang Z, et al. A meta-analysis of extracorporeal shock wave therapy for Peyronie's disease. Int J Impot Res 2016;28:161-6.

13. Hatzimouratidis K, Eardley I, Giuliano F, et al. EAU guidelines on penile curvature. Eur Urol 2012;62:543-52

14. Hellstrom WJ, Bivalacqua TJ. Peyronie's disease: etiology, medical, and surgical therapy. J Androl 2000;21:347-54.

15. Nelson CJ, Diblasio C, Kendirci M, et al. The chronology of depression and distress in men with Peyronie's disease. J Sex Med 2008;5:1985-90.

16. Smith JF, Walsh TJ, Conti SL, et al. Risk factors for emotional and relationship problems in Peyronie's disease. J Sex Med 2008;5:2179-84

17. Thong ISK, Jensen MP, Miró J, Tan G. The validity of pain intensity measures: what do the NRS, VAS, VRS, and FPS-R measure? Scand J Pain 2018;18:99-107.

18. Cappelleri JC, Rosen RC, Smith MD, et al. Diagnostic 
evaluation of the erectile function domain of the International Index of Erectile Function. Urology 1999;54:346-51.

19. Filocamo MT, Serati M, Li Marzi V. et al. The Female Sexual Function Index (FSFI): Linguistic validation of the Italian version. J Sex Med 2014;11:447-53.

20. Wiegel M, Meston C, Rosen R. et al. The female sexual function index (FSFI): cross-validation and development of clinical cutoff scores. J Sex Marital Ther 2005;31:1-20.

21. Nesbit RM. Congenital curvature of the phallus: report of three cases with description of corrective operation. J Urol 1965:93:230.

22. Martenstein C, Peruth J, Hamza A, et al. The role of Nesbit's procedure in surgical reconstruction of penile deviation. GMS Interdiscip Plast Reconstr Surg DGPW 2012;1:Doc06.

23. Iacono F, Prezioso D, Ruffo A, et al. Tunical plication in the management of penile curvature due La Peyronie's disease. Our experience on 47 cases. BMC Surg 2012;12:S25.

24. Gelbard MK, Dorey F, James K. The natural history of Peyronie's disease. J Urol 1990;144:1376-9.

25. Rosen R, Catania J, Lue T, et al. Impact of Peyronie's disease on sexual and psycho- social functioning: Qualitative findings in patients and controls. J Sex Med 2008;5:1977-84.

26. Shindel A, Quayle S, Yan Y, et al. Sexual dysfunction in female partners of men who have undergone radical prostatectomy correlates with sexual dysfunction of the male partner. J Sex Med 2005;2:833-41.

27. Limoncin E, Tomassetti M, Gravina GL, et al. Premature ejaculation results in female sexual distress: standardization and validation of a new diagnostic tool for sexual distress. J Urol 2013;189:1830-5.

28. Jiann BP, Su CC, Tsai JY. Is female sexual function related to the male partners' erectile function? J Sex Med 2013;10:420-9.

Cite this article as: Illiano E, Trama F, Mancini V, Ruffo A, Romeo G, Riccardo F, Fabi C, Carrieri G, Crocetto F, Iacono F, Costantini E. Peyronie's disease may negatively impact the sexual experience of a couple and female sexual function: a single center study. Transl Androl Urol 2021;10(2):555-561. doi: $10.21037 /$ tau-20-1067
29. Frank JE, Mistretta P, Will J, et al. Diagnosis and treatment of female sexual dysfunction Am Fam Physician 2008;77:635-42.

30. Krychman ML. Vaginal estrogens for the treatment of dyspareunia. J Sex Med 2011;8:666-74.

31. Cagnacci A, Venier M. Female sexuality and vaginal health across the menopausal age. Menopause 2020;27:14-9.

32. Wallen K, Lloyd EA. Female sexual arousal: genital anatomy and orgasm in intercourse. Horm Behav 2011;59:780-92.

33. Davis S, Ferrar S, Sadikaj G, et al. Shame, Catastrophizing, and Negative Partner Responses Are Associated With Lower Sexual and Relationship Satisfaction and More Negative Affect in Men With Peyronie's Disease. J Sex Marital Ther 2017;43:264-76.

34. Cocci A, Russo GI, Salonia A, et al. Predictive Factors of Patients' and Their Partners' Sexual Function Improvement After Collagenase Clostridium Histolyticum Injection for Peyronie's Disease: Results From a MultiCenter Single-Arm Study. J Sex Med 2018;15:716-21.

35. Goldstein I, Knoll LD, Lipshultz LI, et al. Changes in the Effects of Peyronie's Disease After Treatment With Collagenase Clostridium histolyticum: Male Patients and Their Female Partners. Sex Med 2017;5:e124-30.

36. Cayan S, Bozlu M, Canpolat B, et al. The assessment of sexual functions in women with male partners complaining of erectile dysfunction: does treatment of male sexual dysfunction improve female partner's sexual functions? J Sex Marital Ther 2004;30:333-41.

37. Goldstein I, Fisher WA, Sand M, et al. Women's sexual function improves when partners are administered vardenafil for erectile dysfunction: a prospective, randomized, double-blind, placebo-controlled trial. J Sex Med 2005;2:819-32.

38. Greenstein A, Abramov L, Matzkin H, et al. Sexual dysfunction in women partners of men with erectile dysfunction. Int J Impot Res 2006;18:44-6. 